\section{Perspective}

J Prev Med Public Health 2020;53:26-28 https://doi.org/10.3961/jpmph.19.315

pISSN 1975-8375 elSSN 2233-4521
Journal of

Preventive Medicine

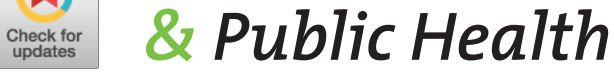

\title{
Characteristics of Heat Waves From a Disaster Perspective
}

\author{
Do-Woo Kim, Chaeyoung Kwon, Jineun Kim, Jong-Seol Lee \\ National Disaster Management Research Institute, Ulsan, Korea
}

In September 2018, heat waves were declared to be a type of natural disaster by the Framework Act on the Management of Disasters and Safety. The present study examined the characteristics of heat waves from the perspectives of meteorological phenomena and health damage. The government's efforts to minimize the damages incurred by heat waves are summarized chronologically. Furthermore, various issues pertaining to heat waves that are being raised in our society despite the government's efforts are summarized by analyzing big data derived from reported news and academic articles.

Key words: Climate change, Extreme heat, Heat stroke, Government, Policy

In Korea, a period is defined as a heat wave if the daily maximum temperature is $33^{\circ} \mathrm{C}$ or higher, according to the heat wave special report issued by the Korea Meteorological Administration (KMA). In Korea, between 1981 and 2010, heat waves averaged 10.1 days annually, based on observations made at 45 weather stations distributed throughout the country. The highest number of heat wave days (31.5) occurred in 2018. The average annual duration of heat waves was 8.2 days in the 1980 s, but increased to 10.4 days in the 1990s and 10.2 days in the 2000s; in the 2010s, the duration of heat waves increased even more sharply to an average of 15.5 days. In 2018, the highest temperature in Korea's meteorological history, $41.0^{\circ} \mathrm{C}$, was recorded in Hongcheon.

The most serious type of damage incurred by heat waves is to health. Health damage caused by heat waves can be divided into 2 categories. The first category comprises heat-related illnesses (HRI) directly caused by high temperatures, such as heat

Received: November 22, 2019 Accepted: January 13, 2020

Corresponding author: Do-Woo Kim, PhD

National Disaster Management Research Institute, 365 Jongga-ro,

Jung-gu, Ulsan 44538, Korea

E-mail: dow1112@korea.kr

This is an Open Access article distributed under the terms of the Creative Commons Attribution Non-Commercial License (https://creativecommons.org/licenses/bync/4.0/) which permits unrestricted non-commercial use, distribution, and reproduction in any medium, provided the original work is properly cited. stroke. In Korea and Japan, heat wave damage statistics present the number of people who suffered from these diseases. Due to the impossibility of monitoring HRI throughout the entire nation in real time, data collected from emergency medical institutions (in Korea) and emergency transportation services (in Japan) are monitored. During the extraordinary heat wave summer (spanning from May 20 to September 10) of 2018 in Korea, the number of heat-related deaths reported by the Korea Centers for Disease Control and Prevention (KCDC) in real time was 48 , and a year later, the final total number of heat-related deaths revealed in Statistics Korea's cause-of-death statistical report was 147. The second category of health damage caused by heat waves includes cases in which an underlying disease is exacerbated by the indirect effects of high temperatures. This type of damage is most frequently estimated by calculating the excess mortality attributable to heat waves that occurred during the heat wave period. In the United Kingdom and France, the number of excess deaths is used to gauge the overall amount impact of a heat wave. This value can only be estimated after the completion of data collection pertaining to the number of deaths in the population; thus, the calculation process takes several weeks in the United Kingdom and 1 to 2 years in Korea. In Korea, during the heat wave in 1994, 92 people died of HRI [1], and 3384 excess deaths were recorded [2].

From the perspective of natural phenomena, heat waves oc- 
cur more slowly and over a wider area than typhoons, heavy rain, heavy snow, and strong winds. Consequently, the forecast accuracy for heat waves is fairly high. The damage caused by other natural disasters mostly results from external physical forces such as flooding and collapse, but in heat waves, health problems occur mainly due to bodily exposure to high temperatures. Therefore, the damage caused by heat waves is strongly affected not only by heat waves themselves as natural phenomena, but also by the state of individuals' health, residences, and working conditions. In Korea, the death toll from other natural disasters has declined conspicuously in recent years, whereas the death toll from heat waves has increased. The total number of deaths caused by other natural disasters (typhoons, heavy rain, and heavy snow) in the last 5 years (2014-2018) was 21 , while the total number of heat wave-related deaths due to $\mathrm{HRI}$, as reported by the KCDC, was 4 times the number incurred by other natural disasters, totaling 88 deaths.

National efforts to reduce the effects of heat waves began in earnest in 2005. Since 2005, central ministries and local governments have collaborated with the Ministry of the Interior and Safety to implement annual countermeasures against intense heat. Since 2008, heat waves have been included in the special weather report issued by the KMA, and since 2010, the $\mathrm{KCDC}$ has monitored the status of $\mathrm{HRI}$ in real time during the summer. As of 2019, 508 medical institutions, constituting almost all nationally-designated emergency medical institutions, voluntarily participate in the aforementioned monitoring process. In 2012, the Act on the Prevention of and Countermeasures against Agricultural and Fishery Disasters classified heat waves as a type of agricultural disaster, providing a basis for financial support or assistance to compensate for the agricultural damages caused by heat waves. In 2017, the Rules on Occupational Safety and Health Standards mandated that employers must provide shaded areas that can be used for breaks when workers are exposed to heat waves and are working outdoors. In 2018, the most basic law on disasters, the Framework Act on the Management of Disasters and Safety, declared heat waves to be a type of natural disaster.

After the historic heat wave in 2018, social interest in heat waves has peaked higher than ever before. During the summer of 2019, more than 13000 articles pertaining to heat waves were published [3]. The most critiqued social issue focused on the health risks of outdoor workers required to be directly exposed to high temperatures during a heat wave. The fact that during the heat wave, the majority of outdoor construction workers were working in an environment in which they could not rest properly, despite the Rules on Occupational Safety and Health Standards, was criticized. The second issue focused on by the media was the cooling centers operated by central and local governments. Many people were unaware of the existence of such centers, and various problems were pointed out, including poor accessibility for vulnerable groups such as the elderly due to long distances, restricted operating hours on weekends or holidays, and locations at sites such as senior citizen community centers, which rendered them culturally inaccessible to those individuals not served by the facility. Other issues subjected to criticism included the provision of a monitoring system for HRI operated by the KCDC. The HRI monitoring system is currently operated via the voluntary participation of emergency departments nationwide. However, it was pointed out that due to the high volume of emergency situations in emergency rooms, there is a high possibility that reports of HRI may have been overlooked in certain situations.

In the past, research papers on heat waves were primarily concerned with identifying the meteorological mechanisms of heat waves and analyzing the effects of climate change. However, over the prior 5 years, the number of papers dealing with the effects of governmental policies regarding heat waves on the population has dramatically increased. Specifically, topics such as urban environmental factors that aggravate the heat wave phenomenon (e.g., the heat island effect) $[4,5]$, community characteristics that aggravate heat wave damages (e.g., local deterioration) $[6,7]$, and the effects of central and local government policies on reducing heat wave damages $[8,9]$ are being investigated.

Since heat waves have been classified as natural disasters, discussions on policies to reduce heat wave damages have become widespread. As mentioned above, heat waves significantly differ from other natural disasters both in terms of their meteorological characteristics and the damage to health that they inflict. Therefore, the strategy of establishing countermeasures against heat waves by imitating policies for other natural disasters has limitations. In order to devise appropriate countermeasures against heat wave disasters, scientific research to support the implementation of these countermeasures is essential.

\section{Ethics Statement}

This paper is a perspective so it did not need ethical consideration. 


\section{CONFLICT OF INTEREST}

The authors have no conflicts of interest associated with the material presented in this paper.

\section{FUNDING}

None.

\section{ACKNOWLEDGEMENTS}

None.

\section{AUTHOR CONTRIBUTIONS}

Conceptualization: DWK. Funding acquisition: None. Writing original draft: DWK, CK, JK. Writing - review \& editing: JSL.

\section{ORCID}

Do-Woo Kim https://orcid.org/0000-0002-7994-827X

Chaeyoung Kwon https://orcid.org/0000-0003-0782-4064

Jineun Kim https://orcid.org/0000-0003-2088-4010

Jong-Seol Lee https://orcid.org/0000-0002-2528-0948

\section{REFERENCES}

1. Kim DW, Chung JH, Lee JS, Lee JS. Characteristics of heat wave mortality in Korea. Atmosphere 2014;24(2):225-234 (Korean).
2. Kysely J, Kim J. Mortality during heat waves in South Korea, 1991 to 2005: how exceptional was the 1994 heat wave? Clim Res 2009;38(2):105-116.

3. Kim DW, Kwon C, Kim J, Lee M. Assessment and prediction analysis on regional heat wave and cold wave risk. Ulsan: $\mathrm{Na}$ tional Disaster Management Research Institute; 2019, p. 125134 (Korean).

4. Kwon Y. Estimation and countermeasure of the heat wave cause of Daegu Metropolitan basin from the urban structural dimension. Korea Spat Plann Rev 2018;98(98):23-35 (Korean).

5. Kim MY, Moon ES. The research of planning method of adaption for old residential neighborhoods according to heat wave and urban heat-island phenomena-focused on Gun-Ja dong, Gwang-Jin gu. KIEAE J 2016;16(4):31-39 (Korean).

6. Kim EJ, Kim H. Effect modification of individual- and regionalscale characteristics on heat wave-related mortality rates between 2009 and 2012 in Seoul, South Korea. Sci Total Environ 2017;595:141-148.

7. Kim DW, Deo RC, Lee JS, Yeom JM. Mapping heatwave vulnerability in Korea. Nat Hazards (Dordr) 2017;89(1):35-55.

8. Yang $\mathrm{HJ}$, Yoon $\mathrm{H}$. Measuring the efficiency of heat-wave action programs in urban environments: using heat-related illness data in Seoul, South Korea. J Korean Urban Manag Assoc 2019; 32(1):31-45 (Korean).

9. Heo S, Nori-Sarma A, Lee K, Benmarhnia T, Dominici F, Bell ML. The use of a quasi-experimental study on the mortality effect of a heat wave warning system in Korea. Int J Environ Res Public Health 2019;16(12):2245. 